University of Nebraska - Lincoln

DigitalCommons@University of Nebraska - Lincoln

5-1997

\title{
Pathogenicity of Escherichia coli 0157:H7 in the Intestines of Neonatal Calves
}

\author{
Evelyn A. Dean-Nystrom \\ Pre-Harvest Food Safety and Enteric Diseases Research Unit, evelyn.nystrom@ars.usda.gov \\ Brad T. Bosworth \\ USDA Agricultural Research Service \\ William C. Cray Jr. \\ USDA-ARS
}

Harley W. Moon

lowa State University

Follow this and additional works at: https://digitalcommons.unl.edu/usdaarsfacpub

Part of the Agricultural Science Commons

Dean-Nystrom, Evelyn A.; Bosworth, Brad T.; Cray, William C. Jr.; and Moon, Harley W., "Pathogenicity of Escherichia coli 0157:H7 in the Intestines of Neonatal Calves" (1997). Publications from USDA-ARS / UNL Faculty. 928.

https://digitalcommons.unl.edu/usdaarsfacpub/928

This Article is brought to you for free and open access by the U.S. Department of Agriculture: Agricultural Research Service, Lincoln, Nebraska at DigitalCommons@University of Nebraska - Lincoln. It has been accepted for inclusion in Publications from USDA-ARS / UNL Faculty by an authorized administrator of DigitalCommons@University of Nebraska - Lincoln. 


\title{
Pathogenicity of Escherichia coli O157:H7 in the Intestines of Neonatal Calves
}

\author{
EVELYN A. DEAN-NYSTROM, ${ }^{1 *}$ BRAD T. BOSWORTH,${ }^{1}$ WILLIAM C. CRAY, JR., ${ }^{1}$ \\ AND HARLEY W. MOON ${ }^{2}$ \\ Enteric Diseases and Food Safety Research Unit, National Animal Disease Center, USDA Agricultural Research Service, \\ Ames, Iowa 50010, ${ }^{1}$ and Department of Pathology, Iowa State University, Ames, Iowa $50011^{2}$
}

Received 5 November 1996/Returned for modification 31 January 1997/Accepted 16 February 1997

\begin{abstract}
Cattle are an important reservoir of Shiga toxin-producing enterohemorrhagic Escherichia coli (EHEC) 0157:H7 strains, foodborne pathogens that cause hemorrhagic colitis and hemolytic uremic syndrome in humans. EHEC 0157:H7 strains are not pathogenic in calves $>3$ weeks old. Our objective was to determine if EHEC 0157:H7 strains are pathogenic in neonatal calves. Calves <36 h old inoculated with EHEC 0157:H7 developed diarrhea and enterocolitis with attaching and effacing (A/E) lesions in both the large and small intestines by $18 \mathrm{~h}$ postinoculation. The severity of diarrhea and inflammation, and also the frequency and extent of $\mathbf{A} / \mathbf{E}$ lesions, increased by 3 days postinoculation. We conclude that EHEC 0157:H7 strains are pathogenic in neonatal calves. The neonatal calf model is relevant for studying the pathogenesis of EHEC 0157:H7 infections in cattle. It should also be useful for identifying ways to reduce EHEC 0157:H7 infections in cattle and thus reduce the risk of EHEC 0157:H7 disease in humans.
\end{abstract}

Escherichia coli strains of serotype O157:H7 belong to a family of pathogenic $E$. coli called enterohemorrhagic $E$. coli (EHEC) strains that cause hemorrhagic colitis, bloody or nonbloody diarrhea, and hemolytic uremic syndrome in humans. EHEC strains are characterized by the production of cytotoxins called Shiga toxins (Stx1 and Stx2) or verotoxins that induce microvascular changes in vivo, are paralytic and lethal for mice, and are cytotoxic for selected cell lines in vitro $(19,29,37)$. EHEC O157:H7 strains colonize and produce characteristic attaching and effacing $(\mathrm{A} / \mathrm{E})$ lesions in the intestines of gnotobiotic piglets, rabbits, and chickens and produce $\mathrm{A} / \mathrm{E}$ lesions in selected cell lines in vitro $(22,45)$. A/E lesions have not been detected in EHEC-infected mice (42) or in humans with EHEC O157:H7 infection (13, 15, 17, 20, 21, 27, 32-34).

EHEC strains can be food-borne pathogens, and cattle are important reservoirs of EHEC 0157:H7 strains. Food-borne outbreaks have on several occasions been attributed to the consumption of bovine products, especially contaminated and improperly cooked hamburger and raw milk $(14,19,38,45)$. The isolation of EHEC 0157:H7 from the feces of healthy cattle $(4,10,14-16,43)$, from packaged bovine products (14), and from produce contaminated by bovine manure (6) supports the epidemiologic evidence of a link between human disease and consumption of bovine manure-contaminated products. One strategy for reducing the risk of EHEC $\mathrm{O} 157: \mathrm{H} 7$ infections in humans is to reduce the prevalence of EHEC 0157:H7 infection in cattle. To accomplish this, we must first understand the pathogenesis of EHEC O157:H7 infection in cattle.

The prevalence of EHEC O157:H7 in the feces of dairy calves and feedlot cattle is low. These bacteria have been isolated from 0.3 to $2.2 \%$ of fecal samples collected from healthy calves or cattle in the United States, Canada, the United Kingdom, Germany, and Spain $(1,14)$. Following experimental inoculation with $E$. coli 3081, an EHEC O157:H7 strain isolated from a healthy calf, calves ( 3 to 14 weeks old)

* Corresponding author. Phone: (515) 239-8376. Fax: (515) 2398458. E-mail: enystrom@nadc.ars.usda.gov. and adult cattle ( $>1$ year old) shed variable quantities of EHEC O157:H7 in their feces for variable periods (sometimes more than 6 months [7]). Calves shed larger numbers of strain 3081 and for longer periods than adults. Experimentally infected cattle remained healthy and free of histological lesions (7). Thus, EHEC O157:H7 strains apparently are not pathogenic in cattle $\geq 3$ weeks old. However, it is possible that the EHEC O157:H7 healthy calf isolate that was used in earlier studies is less pathogenic than EHEC O157:H7 strains that cause disease in humans. It is also possible that EHEC O157:H7 strains are pathogenic only in very young calves $(<3$ weeks old). Age-related resistance to disease is characteristic of infections by other E. coli pathotypes such as K99 and 987P-fimbriate enterotoxigenic $E$. coli in cattle and pigs and enteropathogenic $E$. coli in rabbits $(5,8,25,46)$.

EHEC O157:H7 strains associated with disease in humans are pathogenic in neonatal pigs $(11,12,40,41)$. We hypothesized that EHEC O157:H7 strain 3081, the healthy calf isolate used in earlier studies, is also pathogenic for neonatal pigs and that EHEC O157:H7 strains are pathogenic in neonatal $(<3$ week-old) calves. Several lines of evidence support this latter hypothesis. An EHEC O157:H7 isolate from a $<3$-week-old calf with diarrhea in Argentina is similar to EHEC O157:H7 isolates that are associated with human outbreaks (Stx positive, sorbitol negative, $\beta$-glucuronidase negative [31]). Other bovine enteropathogenic and verotoxigenic $E$. coli isolates cause diarrhea and $\mathrm{A} / \mathrm{E}$ lesions in <3-week-old calves (3, 24, 28, 36, 47). EHEC strains colonize and produce $\mathrm{A} / \mathrm{E}$ lesions in several other species, as noted above. It seems likely that EHEC O157:H7 strains also would colonize and produce A/E lesions in cattle. The objectives of this study were (i) to determine if the EHEC O157:H7 calf isolate used in earlier studies is pathogenic for neonatal pigs, (ii) to compare the pathogenicity of the EHEC O157:H7 calf isolate with that of a hamburger isolate implicated in a food-borne outbreak in humans (30), and (iii) to determine if $E$. coli $\mathrm{O} 157: \mathrm{H} 7$ strains are pathogenic in neonatal calves.

(A preliminary account of this work was presented at the 96th General Meeting of the American Society for Microbiology, New Orleans, La., 19 to 23 May 1996.) 
TABLE 1. Findings in CDCD piglets $18 \mathrm{~h}, 3$ days, and 7 days after inoculation with EHEC O157:H7 strains 3081 and 933

\begin{tabular}{ccccc}
\hline \multirow{3}{*}{ Finding } & \multicolumn{2}{c}{$18 \mathrm{~h}$} & 3 days, 933 \\
\cline { 2 - 3 } & $\begin{array}{c}3081 \\
(n=6)\end{array}$ & $\begin{array}{c}933 \\
(n=7)\end{array}$ & $\begin{array}{c}7 \text { days, } 933 \\
(n=3)\end{array}$ \\
\hline
\end{tabular}

A/E lesions in:

Distal colon

Spiral colon

Cecum

Ileum

Jejunum

Duodenum

Vascular necrosis ${ }^{a}$

Intestine

Brain

$\begin{array}{ll}0 & 0 \\ 5 & 3 \\ 6 & 7 \\ 4 & 1 \\ 0 & 0 \\ 0 & 0\end{array}$

$\begin{array}{ll}0 & 1 \\ 3 & 1 \\ 7 & 2 \\ 1 & 2 \\ 0 & 0 \\ 0 & 0\end{array}$

1
1
2
2
0
0

0

3

3

0

0

0

$\begin{array}{clll}0 & 0 & 0 & 1 \\ \mathrm{ND}^{b, c} & 0^{c} & 1 & 3\end{array}$

${ }^{a}$ Vascular lesions consisted of segmental necrosis of myocytes in the tunica media of arterioles.

${ }^{b} \mathrm{ND}$, not determined.

${ }^{c}$ Brain sections collected from only two pigs at $18 \mathrm{~h}$ after inoculation with strain 933 .

\section{MATERIALS AND METHODS}

Bacterial strains and inocula. EHEC O157:H7 strain 3081 was isolated from a calf during the U.S. Department of Agriculture's National Animal Health Monitoring System National Dairy Heifer Evaluation Project (39). This strain is resistant to kanamycin and ampicillin and hybridizes with probes for stx 1 and stx2 (Shiga toxins Stx1 and Stx2), eae (A/E protein), and CVD419 (the EHEC large plasmid) $(7,18,23,29)$. Cray and Moon used strain 3081 to define the magnitude and duration of fecal shedding of EHEC O157:H7 by 3- to 14-week-old calves and adult cattle (7). EHEC O157:H7 strain 933 was isolated in 1982 from hamburger incriminated in the first documented EHEC fast-food chain outbreak in the United States $(30,33,44)$. This strain produces Stx1 and Stx2, hybridizes to probes for eae and CVD419, and is resistant to streptomycin. E. coli 123 (serogroup O43:H28) was isolated from a healthy pig, is nonpathogenic, does not produce Stx1 or Stx2, and is probe negative for eae and CVD419 $(2,26)$. A spontaneous nalidixic acid-resistant mutant of strain 123 was used for some experiments. Stock inocula containing approximately $10^{10} \mathrm{CFU} / \mathrm{ml}$ were prepared as previously described (35) and stored in $1-\mathrm{ml}$ aliquots at $-80^{\circ} \mathrm{C}$ until used.

Bacteriologic examination. Sorbitol-negative EHEC O157:H7 was quantitated on sorbitol MacConkey agar containing potassium tellurite $(2.5 \mu \mathrm{g} / \mathrm{ml})$. Kanamycin $(100 \mu \mathrm{g} / \mathrm{ml})$ or streptomycin $(100 \mu \mathrm{g} / \mathrm{ml})$ was added to select for EHEC O157:H7 strain 3081 or EHEC O157:H7 strain 933, respectively. Selected sorbitol-negative colonies were tested for $\mathrm{O} 157$ antigens by latex bead agglutination assay (Oxoid, Unipath Ltd., Ogdensburg, N.Y.). E. coli 123 was quantitated on MacConkey agar containing $20 \mu \mathrm{g}$ of nalidixic acid per $\mathrm{ml}$.

Histologic studies. Tissues were fixed in neutral buffered $10 \%$ formalin, dehydrated with alcohol, embedded in paraffin, sectioned at $4 \mu \mathrm{m}$, and stained with hematoxylin and eosin (H\&E). Stained tissue slides were coded and examined by the use of light microscopy.
Electron microscopy (EM) studies. Samples of cecum, colon, rectum, or ileum from some animals were fixed in $3 \%$ glutaraldehyde (in $0.1 \mathrm{M}$ sodium cacodylate buffer [pH 7.4] with 5\% sucrose) and embedded in Eponate 812 resin (Ted Pella, Inc., Redding, Calif.). Some samples were removed from formalin and postfixed in glutaraldehyde. Ultrathin sections were stained with lead citrate and uranyl acetate and examined with a Philips 410 electron microscope.

Immunoperoxidase staining with anti-O157:H7. O157:H7-positive bacteria were identified in paraffin-embedded, formalin-fixed tissues by indirect immunoperoxidase staining using the MicroProbe System (Fisher Scientific, Pittsburgh, $\mathrm{Pa}$.) and sequential incubations with goat anti-O157:H7 (1:20,000; Kirkegaard \& Perry Laboratories, Inc., Gaithersburg, Md.), biotinylated anti-goat (Vector Laboratories, Inc., Burlingame, Calif.), and Biostain Super ABC (Biomeda, Foster City, Calif.). Goat anti-salmonella (1:20,000; Kirkegaard \& Perry) was used as negative control serum. Horseradish peroxidase (HRPO) slides were coded and examined by light microscopy by an investigator different from the one who examined the $\mathrm{H} \& \mathrm{E}$ slides.

Pathogenicity of EHEC 0157:H7 strains in neonatal piglets. Neonatal piglets are a useful in vivo model for demonstrating the pathogenicity of EHEC O157:H7 strains $(11,12,40,41)$. Gnotobiotic and cesarean section-derived, colostrum-deprived (CDCD) piglets were used to test the hypothesis that strain 3081 is not pathogenic. Two 1-day-old gnotobiotic piglets were inoculated with $10^{9} \mathrm{CFU}$ of EHEC O157:H7 strain 3081 or 933 (one piglet per strain), euthanatized, necropsied, and examined histologically $18 \mathrm{~h}$ after inoculation at South Dakota State University, Brookings, by D. H. Francis and L. D. Holler, as previously described (12)

CDCD $<8$-h-old piglets from four litters were inoculated via stomach tubes with $10^{10}$ CFU of EHEC O157:H7 strain 3081 or 933 or E. coli control strain 123 Inoculated animals were maintained in individual plastic cages on a diet consisting of autoclaved SPF-LAC (Borden, Elgin, Ill.) given three times daily. Piglets received $270 \mathrm{ml}$ of SPF-LAC on day 1 and $360 \mathrm{ml}$ per day on days 2 to 7 . Piglets were euthanatized with sodium pentobarbital $18 \mathrm{~h}$ to 7 days postinoculation (Table 1). During the period between inoculation and necropsy, piglets were observed for signs of disease. At necropsy, sections of distal colon, spiral colon, cecum, terminal ileum, jejunum, duodenum, and brain stem were collected for histopathologic and HRPO examinations.

Pathogenicity of EHEC 0157:H7 strains in neonatal calves. Colostrum-deprived and colostrum-fed neonatal calves $<12 \mathrm{~h}$ and 30 to $36 \mathrm{~h}$ old were used (Table 2). Male calves were removed from their dams before they suckled colostrum, transported to the National Animal Disease Center, and housed individually in pens on concrete floors with wood shavings. Colostrum-deprived $<12$-h-old calves were inoculated via suckling with milk replacer containing $10^{10}$ CFU of EHEC O157:H7 strain 3081 or 933 or nonpathogenic strain 123. Calves were fed milk replacer without antibiotics (Scooter Feeds, Arbie Mineral Feed Co., Inc., Marshalltown, Iowa) 8 to $9 \mathrm{~h}$ postinoculation and at 8 -h intervals, observed for signs of disease (by an investigator different from those who did histologic and HRPO studies), and euthanatized with sodium pentobarbital $18 \mathrm{~h}$ or 3 days postinoculation. At necropsy, rectal and cecal contents were collected and frozen at $-80^{\circ} \mathrm{C}$ for bacteriology. Sections from rectum, spiral colon, cecum, terminal ileum, jejunum, duodenum, abomasum, esophagus, and tonsils were collected for histopathologic and HRPO examinations. Samples of rectum, colon, cecum, and ileum from some animals were collected for EM.

To determine the pathogenicity of EHEC O157:H7 strains in calves that had ingested colostrum, neonatal colostrum-deprived calves were fed twice on day 1 with colostrum or milk replacer. All calves were fed milk replacer the morning of day 2. On the afternoon of day 2, when calves were 30 to $36 \mathrm{~h}$ old, four colostrum-fed and three colostrum-deprived calves were inoculated with milk replacer containing $10^{10} \mathrm{CFU}$ of EHEC O157:H7 strain 3081. One colostrum-

TABLE 2. Findings in neonatal calves at $18 \mathrm{~h}$ and 3 days after inoculation with EHEC O157:H7 or nonpathogenic E. coli

\begin{tabular}{|c|c|c|c|c|c|c|c|}
\hline \multicolumn{4}{|c|}{ Inoculation } & \multirow{2}{*}{\multicolumn{4}{|c|}{ No. ${ }^{b}$ of animals with: }} \\
\hline \multicolumn{2}{|c|}{ Calf } & \multirow{2}{*}{$\begin{array}{c}\text { Duration } \\
\text { of expt }\end{array}$} & \multirow{2}{*}{$\begin{array}{l}\text { Inoculum } \\
\text { strain }^{a}\end{array}$} & & & & \\
\hline Age (h) & Colostrum & & & Diarrhea & Colonic edema & $\mathrm{A} / \mathrm{E}$ lesions & Other ${ }^{c}$ \\
\hline \multirow[t]{3}{*}{$<12$} & No & $18 \mathrm{~h}$ & 933 & $0 / 4$ & $1 / 4$ & $4 / 4$ & \\
\hline & & & 3081 & $2 / 3$ & $2 / 3$ & $3 / 3$ & NI, $3 / 3$ \\
\hline & & & 123 & $0 / 2$ & $0 / 2$ & $0 / 2$ & \\
\hline \multirow{2}{*}{$<12$} & No & 3 days & 3081 & $3 / 3$ & $0 / 2$ & $2 / 2$ & Death, $1 / 3$; VA, $2 / 2$; FHP $1 / 2$; NI, $1 / 2$ \\
\hline & & & 123 & $1 / 2^{d}$ & $0 / 2$ & $1 / 2^{d}$ & \\
\hline \multirow[t]{3}{*}{$30-36$} & No & $18 \mathrm{~h}$ & 3081 & $2 / 3$ & $2 / 3$ & $3 / 3$ & \\
\hline & Yes & & 3081 & $1 / 4$ & $0 / 4$ & $3 / 4$ & \\
\hline & Yes & & 123 & $0 / 1$ & $0 / 1$ & $0 / 1$ & \\
\hline
\end{tabular}

${ }^{a}$ EHEC O157:H7 strain 3081 or 933; nonpathogenic control E. coli O43:H28 strain 123.

${ }^{b}$ Number positive/number tested.

${ }^{c}$ NI, diffuse neutrophil infiltration; FHP, fibrinohemorrhagic pseudomembrane; VA, diffuse atrophy of ileal villi.

${ }^{d}$ Calf with diarrhea had A/E lesions that were not associated with E. coli O157:H7. 
TABLE 3. Distribution and extent of $\mathrm{A} / \mathrm{E}$ lesions in neonatal calves at $18 \mathrm{~h}$ and 3 days after inoculation with EHEC O157:H7 strain 933 or 3081

\begin{tabular}{|c|c|c|c|c|c|}
\hline \multirow{3}{*}{ Tissue } & \multicolumn{5}{|c|}{ Mean A/E score ${ }^{a}$ (range) } \\
\hline & \multirow{2}{*}{$\begin{array}{c}933,<12 \mathrm{~h},{ }^{b} 18 \mathrm{~h}{ }^{c}, \\
\text { no colostrum } \\
(n=4)\end{array}$} & \multirow{2}{*}{$\begin{array}{c}\text { 3081, }<12 \mathrm{~h}, 18 \mathrm{~h}, \\
\text { no colostrum } \\
(n=3)\end{array}$} & \multirow{2}{*}{$\begin{array}{c}\text { 3081, }<12 \mathrm{~h}, 3 \text { days } \\
\text { no colostrum } \\
(n=2)\end{array}$} & \multicolumn{2}{|c|}{$3081,30-36 \mathrm{~h}, 18 \mathrm{~h}$} \\
\hline & & & & $\begin{array}{l}\text { No colostrum } \\
\quad(n=3)\end{array}$ & $\begin{array}{c}\text { Colostrum } \\
(n=4)\end{array}$ \\
\hline Rectum & $0.8(0-2)$ & $2.7(2-3)$ & $3.5(3-4)$ & 0 & $0.3(0-1)$ \\
\hline Colon & $1.0(0-2)$ & $1.7(1-2)$ & $3.0(2-4)$ & $1.0(1-1)$ & $1.5(0-3)$ \\
\hline Cecum & $1.3(0-2)$ & $1.7(1-2)$ & 0 & $0.3(0-1)$ & 0 \\
\hline Ileum & $1.8(1-2)$ & $2.0(1-3)$ & $3.0(3-3)$ & $1.0(0-2)$ & $0.3(0-1)$ \\
\hline Jejunum & 0 & $0.3(0-1)$ & 0 & $0.3(0-1)$ & 0 \\
\hline Duodenum & 0 & 0 & 0 & 0 & 0 \\
\hline Abomasum & 0 & $0.3(0-1)$ & 0 & 0 & 0 \\
\hline
\end{tabular}

${ }^{a} \mathrm{~A} / \mathrm{E}$ scores: 0 , negative; 1, detected only in HRPO-stained sections; 2 to 4, detected in H\&E-stained sections; $2,<10 \%$ of the villi or surface epithelium affected; 3,10 to $50 \%$ of the villi or surface epithelium affected; $4, \geq 50 \%$ of the villi or surface epithelium affected.

${ }^{b}$ Age at inoculation.

${ }^{c}$ Duration.

deprived calf was similarly inoculated with $E$. coli control strain 123 . Calves were euthanatized $18 \mathrm{~h}$ postinoculation, and samples were collected as described above. R. Johnson (Health of Animals Laboratory, Guelph, Ontario, Canada) kindly tested the colostrum for antibodies to Stx1, Stx2, and O157. He found a 1:10,000 neutralizing antibody titer against Stx1 and a 1:1,280 titer against O157 lipopolysaccharide but found no antibodies against Stx2.

\section{RESULTS}

Pathogenicity of EHEC 0157:H7 strains in neonatal piglets. Both of the gnotobiotic piglets had diarrhea and $\mathrm{A} / \mathrm{E}$ lesions in the large intestine at $18 \mathrm{~h}$ after inoculation with EHEC O157:H7 strain 933 or 3081. None of the CDCD piglets developed diarrhea by $18 \mathrm{~h}$ after inoculation with EHEC O157:H7 strain 933 or 3081 or the control strain 123. CDCD piglets had $\mathrm{A} / \mathrm{E}$ bacteria in the colon, cecum, and/or ileum by $18 \mathrm{~h}$ after inoculation with EHEC O157:H7 strain 933 or 3081 (Table 1). A/E lesions were most consistently found in the large intestine. At 3 to 7 days after inoculation with EHEC O157:H7 strain 933, all CDCD piglets had A/E lesions. Five of seven piglets developed ataxia by 3 days postinoculation.

O157: $\mathrm{H}^{+} \mathrm{A} / \mathrm{E}$ bacteria were detected by HRPO staining in all tissue sections from CDCD piglets in which they were detected by $\mathrm{H} \& \mathrm{E}$ staining. In addition, $\mathrm{O} 157: \mathrm{H}^{+} \mathrm{A} / \mathrm{E}$ bacteria (rare to few) were detected by HRPO in 11 sections ( 7 of 21 large intestinal and 4 of 5 small intestinal) from piglets necropsied at $18 \mathrm{~h}$ postinoculation in which no $\mathrm{A} / \mathrm{E}$ bacteria were found by $\mathrm{H} \& \mathrm{E}$. EM examination of colonic and cecal tissues from gnotobiotic and CDCD piglets infected with EHEC 0157:H7 showed intimately attached bacteria, effaced microvilli, host cell cytoplasmic pedestals, and actin accumulation. Some bacteria appeared to be intracellular. Some CDCD piglets infected with EHEC O157:H7 strains also had vascular lesions consisting of segmental necrosis of myocytes in the tunica media of small arteries and arterioles.

No A/E bacteria or vascular lesions were seen in any of the piglets inoculated with $E$. coli control strain 123 .

Pathogenicity of EHEC 0157:H7 strains in colostrum-deprived neonatal calves. EHEC O157:H7 strains 3081 and 933 were pathogenic in neonatal $<12$-h-old colostrum-deprived calves (Table 2). At $18 \mathrm{~h}$ postinoculation, calves had diarrhea, colonic edema, and $\mathrm{A} / \mathrm{E}$ bacteria in the rectum, cecum, colon, and ileum. A/E bacteria also were found in the jejunum and abomasum of one calf. $\mathrm{A} / \mathrm{E}$ bacteria tended to be more frequent and affect more extensive areas in calves inoculated with strain 3081 than in those inoculated with strain 933 (Table 3).

In the 3-day experiment, two of three calves had watery diarrhea at $18 \mathrm{~h}$ after inoculation with strain 3081 and required rehydration therapy. One of these calves died on the second day. Postmortem observations were compatible with enteritis and dehydration as the cause of death. Because of postmortem autolysis, no samples were collected for microscopic examination. The third calf had soft feces on day 1 and watery diarrhea

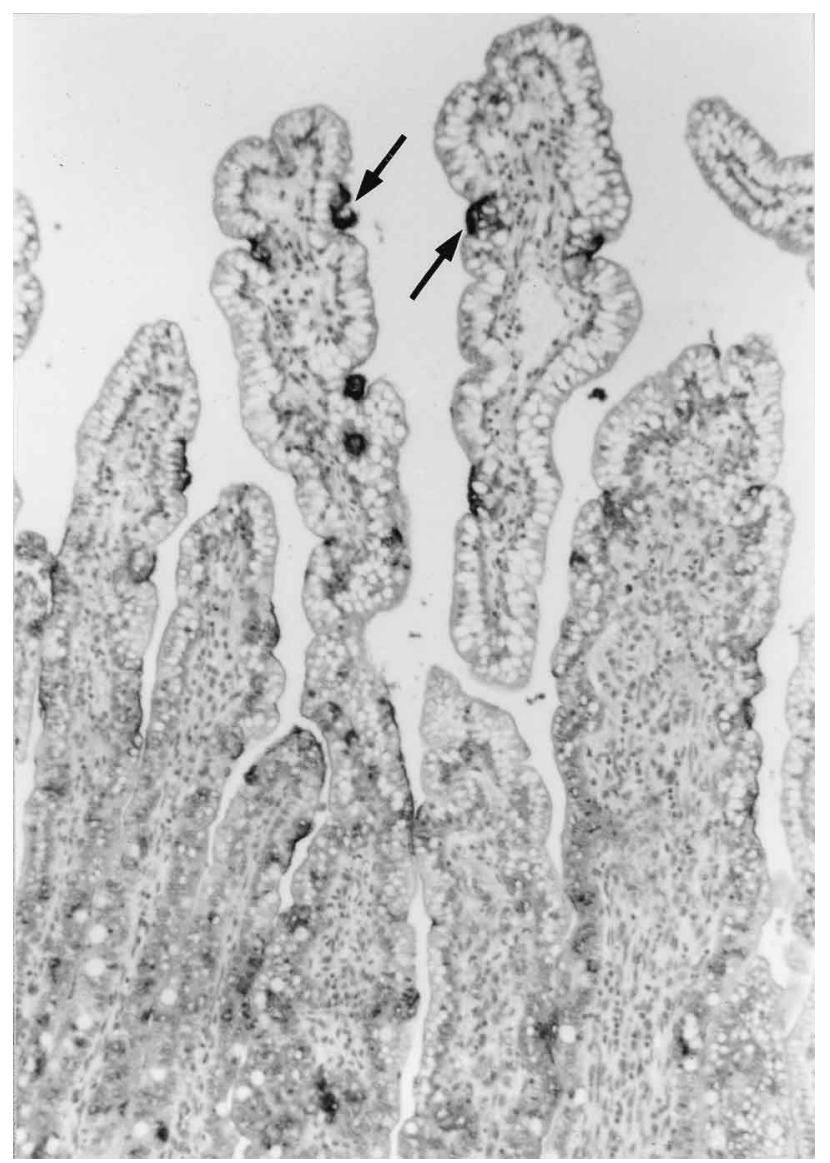

FIG. 1. HRPO-stained section of neonatal calf ileum $18 \mathrm{~h}$ after inoculation with EHEC O157:H7 strain 3081. Immunostained areas (arrows) illustrate colonies of A/E EHEC O157:H7. Most villous epithelium is not colonized and retains the normal, vacuolated, tall columnar morphology. 


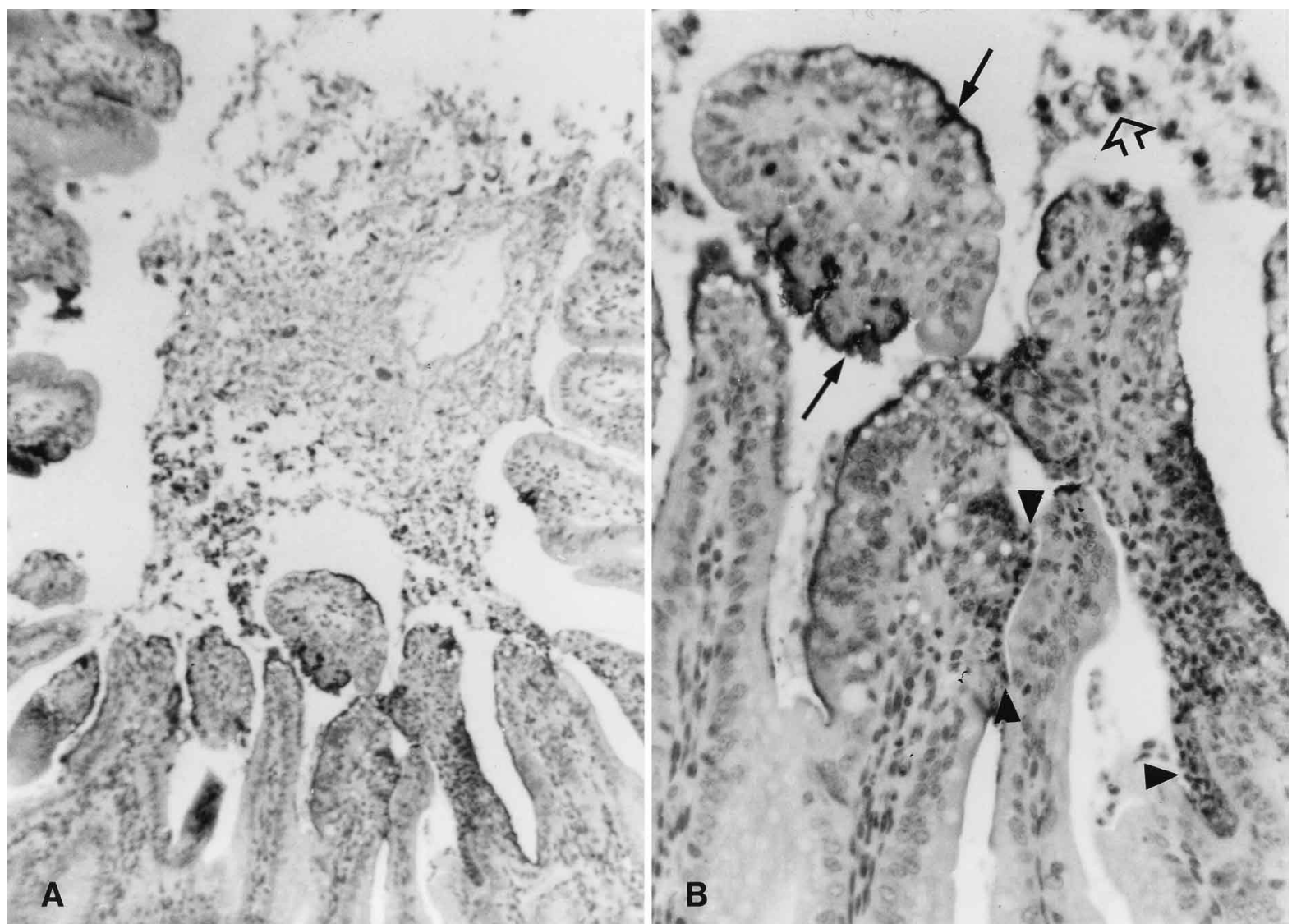

FIG. 2. HRPO-stained section of neonatal calf colon $18 \mathrm{~h}$ after inoculation with EHEC O157:H7 strain 3081. (A) There are scattered colonies of A/E EHEC O157:H7 (dark patches). (B) Higher magnification to illustrate A/E E. coli colonies (arrows), luminal exudate (open arrow), and plugs of luminal neutrophils (arrowheads) streaming between epithelial surfaces.

on day 2 postinoculation but did not require rehydration therapy. Extensive $\mathrm{A} / \mathrm{E}$ lesions were found in colon, rectum, and ileum, but not cecum, of the two calves necropsied on day 3 postinoculation.

At $18 \mathrm{~h}$ postinoculation, no diarrhea or lesions were seen in calves inoculated with control strain 123. At 3 days after inoculation with $E$. coli control strain 123 , one calf had no diarrhea or lesions. The other control calf had diarrhea and $\mathrm{A} / \mathrm{E}$ bacteria in the colon but had $<10^{3} \mathrm{CFU}$ of strain $123 / \mathrm{g}$ of colonic tissue. However, in contrast to principals, the $\mathrm{A} / \mathrm{E}$ bacteria were not detected by HRPO staining for O157:H7.

The occurrence, distribution in intestine, and extent of $\mathrm{A} / \mathrm{E}$ lesions varied among animals. The proportion of animals with $\mathrm{A} / \mathrm{E}$ lesions and the location and extent of $\mathrm{A} / \mathrm{E}$ lesions varied with duration of exposure to EHEC O157:H7. The extent of $\mathrm{A} / \mathrm{E}$ lesions also varied with location in the intestine. There were multifocal areas of degeneration of villous or surface epithelium in which detached and sloughing epithelial cells were prominent. These foci frequently had associated layers of bacteria intimately attached to irregular epithelial surfaces (Fig. 1 and 2). Congestion and prominent neutrophil infiltration were sometimes associated with the foci of epithelial degeneration (Fig. 2). In addition to $\mathrm{A} / \mathrm{E}$ lesions, diffuse neutrophil infiltration was prominent in the large intestine or ileum of calves $18 \mathrm{~h}$ after inoculation (at $<12 \mathrm{~h}$ of age) with EHEC O157:H7 strain 3081. Both of the calves examined 3 days after inoculation with $\mathrm{O} 157: \mathrm{H} 7$ strain 3081 had extensive multifocal areas of $\mathrm{A} / \mathrm{E}$ bacteria in the rectum, colon, and ileum. There was also diffuse atrophy of ileal villi in both calves. In one of these two calves, the ileal lesion was further complicated by diffuse neutrophil infiltration and formation of a pseudomembrane containing blood, fibrin, cellular debris, and neutrophils (Fig. 3).

$\mathrm{A} / \mathrm{E}$ lesions in calves inoculated with EHEC O157:H7 were similar to those in piglets. EM examination of rectum, colon, cecum, and ileum from calves infected with EHEC O157:H7 demonstrated that bacteria were intimately attached to epithelial cells and microvilli were effaced. Some adherent bacteria were associated with host cell cytoplasmic pedestals and electron-dense filaments consistent with actin accumulation in the apical cytoplasm. Some bacteria were intracellular (Fig. 4).

$\mathrm{A} / \mathrm{E}$ bacteria were detected by HRPO staining with antiO157:H7 (Fig. 1 and 2) in all tissue sections from O157:H7inoculated calves in which they were detected by H\&E staining, confirming that the $\mathrm{A} / \mathrm{E}$ bacteria in principals were $\mathrm{EHEC}$ O157:H7. In addition, A/E bacteria (rare to few) were detected by HRPO in 15 sections in which they were not detected during the initial examination of $H \& E$-stained slides. Because of the greater sensitivity of HRPO, A/E lesions initially detected by HRPO and not by H\&E staining were scored as 1 . Lesions initially detected in $\mathrm{H} \& \mathrm{E}$-stained slides were scored from 2 to 4 depending on the extent of villous or surface epithelium associated with $\mathrm{A} / \mathrm{E}$ bacteria (Table 3 ).

EHEC O157:H7 were recovered from rectal or cecal contents from all calves inoculated with EHEC O157:H7 strain 3081 or 933 but not from any calf inoculated with $E$. coli 


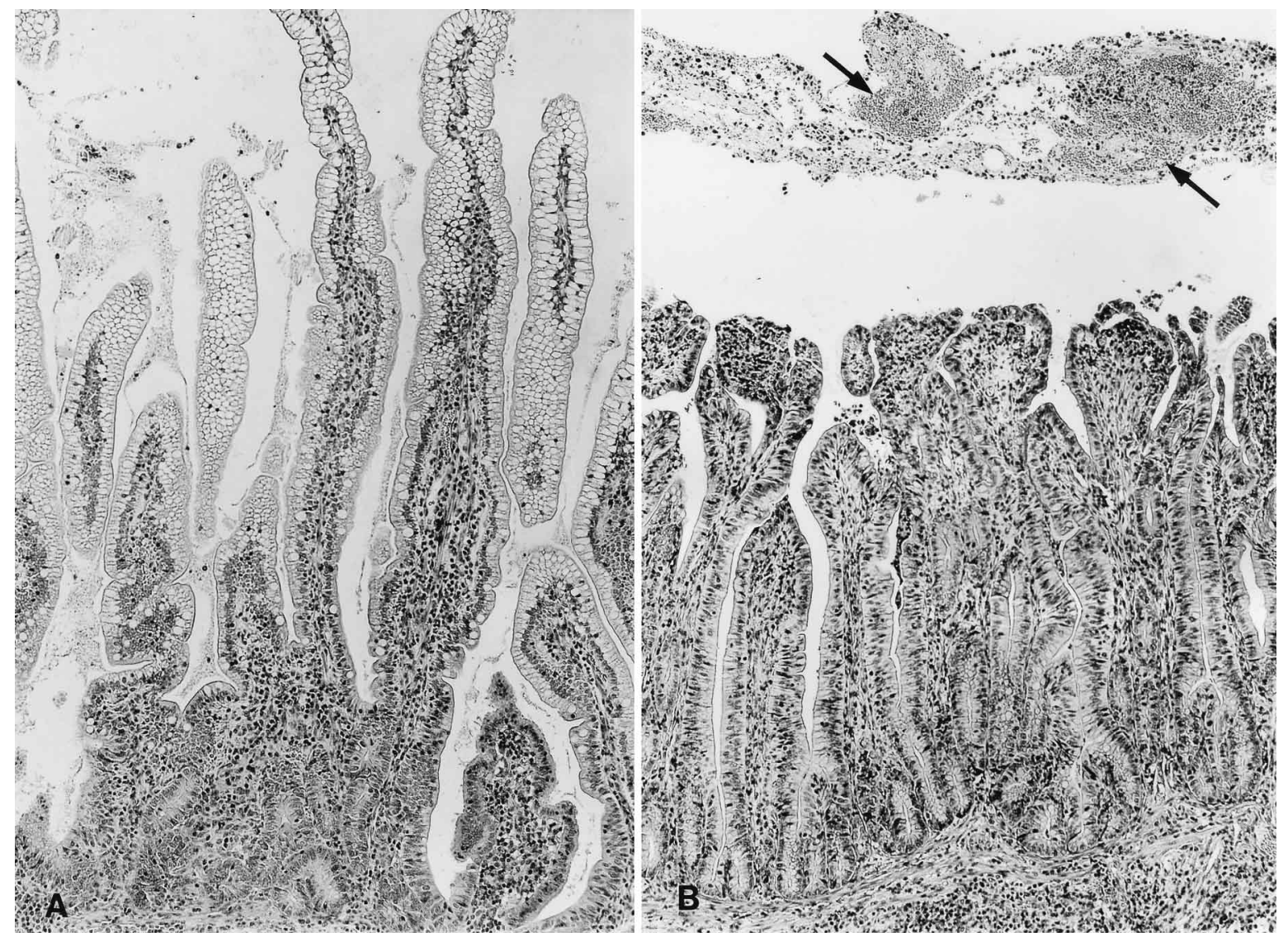

FIG. 3. H\&E-stained sections of neonatal calf ileum. (A) At $18 \mathrm{~h}$ after inoculation with control E. coli strain 123 . The long villi and vacuolated, tall columnar epithelium characteristic of normal neonatal calves are preserved. (B) At 3 days after inoculation with EHEC O157:H7 strain 3081. There is diffuse atrophy of villi. Atrophic villi have irregular, disrupted epithelium at their tips and cellular infiltrates (determined at higher magnification to be neutrophils) in distal lamina propria. Hemorrhage (plugs of erythrocytes at arrows) and fibrinocellular exudate have formed a pseudomembrane in the lumen.

control strain 123. At $18 \mathrm{~h}$ postinoculation, the geometric mean viable counts of EHEC O157:H7 for both sites were $10^{5}$ $\mathrm{CFU} / \mathrm{g}$ of contents (ranges were $10^{3}$ to $10^{8}$ and $10^{3}$ to $10^{6}$ $\mathrm{CFU} / \mathrm{g}$ for rectal and cecal contents, respectively). The two calves necropsied 3 days after inoculation with EHEC O157:H7 had approximately $10^{8}$ and $10^{6} \mathrm{CFU}$ of EHEC O157:H7 per $\mathrm{g}$ of rectal and cecal counts, respectively. Rectal and cecal contents from control calves had approximately $10^{3}$ CFU of E. coli control strain 123 per g of contents.

Pathogenicity of EHEC 0157:H7 in colostrum-fed neonatal calves. EHEC O157:H7 strain 3081 caused diarrhea, colonic edema, and $\mathrm{A} / \mathrm{E}$ lesions in both colostrum-fed and colostrumdeprived calves inoculated at 30 to $36 \mathrm{~h}$ of age (Table 2). However, A/E lesions in both groups were less extensive and occurred less frequently than in calves inoculated with strain 3081 when $<12$ h old (Table 3 ).

\section{DISCUSSION}

EHEC O157:H7 strain 3081 (healthy calf isolate [7]) was at least as pathogenic as EHEC O157:H7 strain 933 (hamburger isolate [30]) in gnotobiotic and CDCD piglets. EHEC O157:H7 infection in CDCD piglets was similar to that in gnotobiotic piglets (references 11, 12, 40, and 41 and this report) except that EHEC O157:H7 bacteria did not cause diarrhea in CDCD piglets by $18 \mathrm{~h}$ postinoculation. The disease in CDCD piglets progressed to include neurological signs and lesions by 3 to 7 days after inoculation, as described for gno- tobiotic pigs $(11,40)$. The CDCD piglet model, like the gnotobiotic piglet model, should be useful for studying virulence attributes of EHEC O157:H7 and other EHEC organisms.

Furthermore, EHEC O157:H7 bacteria were pathogenic in neonatal ( $<36$-h-old) calves. Diarrhea was the only clinical manifestation at $18 \mathrm{~h}$ postinoculation and occurred in only some infected animals. Inflammation and $\mathrm{A} / \mathrm{E}$ lesions in both the large and small intestines were common observations. Ingestion of colostrum which contained antibodies against Stx1 and O157 did not prevent neonatal calves from developing the disease.

At $18 \mathrm{~h}$ after calves were inoculated with EHEC O157:H7, the incidence and severity of diarrhea, the frequency and severity of $\mathrm{A} / \mathrm{E}$ lesions, and the numbers of EHEC O157:H7 were quite variable. In some calves, $\mathrm{A} / \mathrm{E}$ lesions were so infrequent that they could be detected only by HRPO staining, which was more sensitive than $\mathrm{H} \& \mathrm{E}$ staining. By increasing the length of time between inoculation and necropsy from $18 \mathrm{~h}$ to 3 days, we demonstrated that EHEC O157:H7 strain 3081 induced extensive $\mathrm{A} / \mathrm{E}$ lesions and severe, sometimes fatal diarrhea in neonatal calves. Striking disease with hemorrhage and pseudomembrane formation, reminiscent of some human cases of hemorrhagic colitis $(17,20,21,27,32-34)$ and some $\mathrm{A} / \mathrm{E}$ E. coli-associated colitis cases in calves (36), occurred in one calf 3 days postinoculation.

EHEC 0157:H7 pathogenicity in cattle appears to be age related, even within the neonatal period. The virulence of 


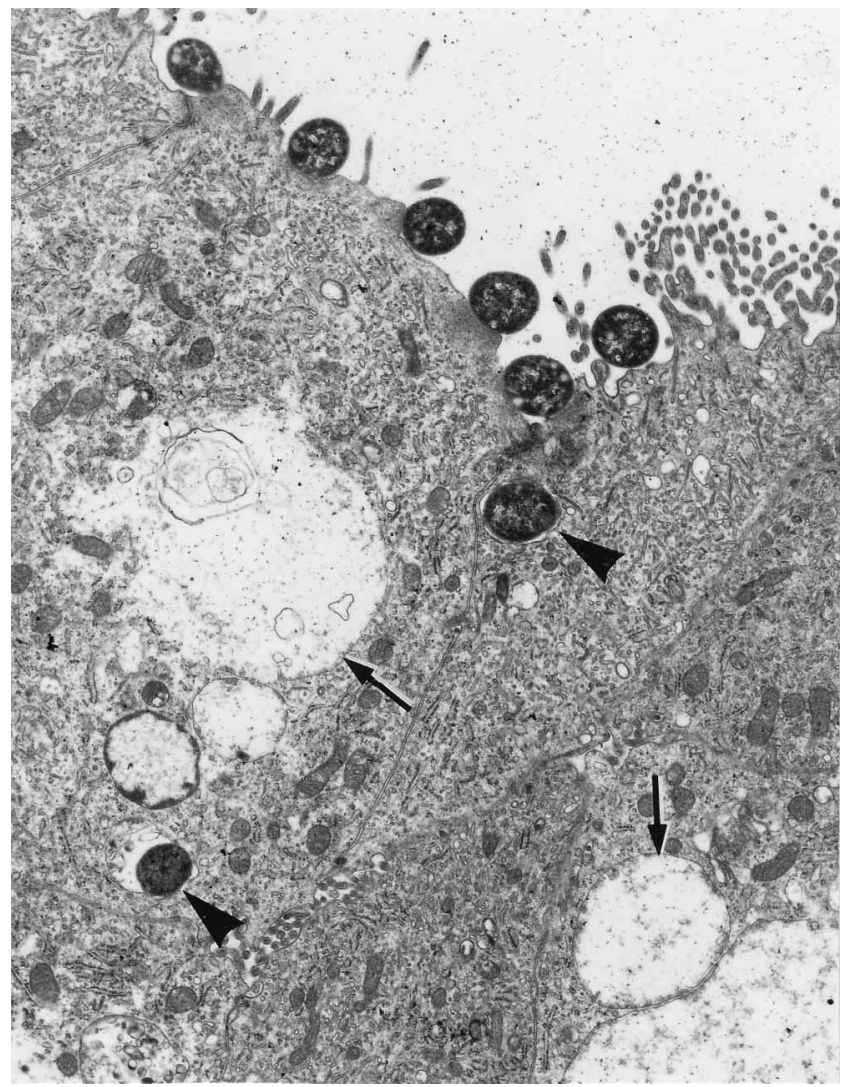

FIG. 4. Electron micrograph of absorptive cells from the ileum of a neonatal calf $18 \mathrm{~h}$ after inoculation with EHEC O157:H7 strain 3081. Bacteria are intimately attached to absorptive cell membranes. Absorptive cell microvilli have been effaced to the left but remain in the uncolonized area to the right. There are electron-dense filaments (presumably polymerized actin) in host cytoplasm subjacent to attached bacteria. Vacuolation of absorptive cells (arrows) is normal at this age. Two bacteria appear to be intracellular in vacuoles (arrowheads).

EHEC O157:H7 bacteria was greater in $<12$-h-old calves than in 30- to 36-h-old calves. A/E lesions were less frequent and less extensive in calves inoculated at 30 to $36 \mathrm{~h}$ of age than in calves inoculated before they were $12 \mathrm{~h}$ old. A similar age specificity has been described for other bovine A/E $E$. coli isolates $(3,15,24,47)$.

$\mathrm{A} / \mathrm{E}$ lesions associated with EHEC O157:H7 infection in neonatal calves were similar to those observed in gnotobiotic and CDCD pigs (references 12 and 41 and this report). Vascular lesions were detected in neonatal piglets by day 3 postinoculation with EHEC O157:H7. No vascular lesions were found in calves infected with $E$. coli $\mathrm{O} 157: \mathrm{H} 7$, but this study included only two calves that survived to day 3 after inoculation.

HRPO staining was more sensitive than $H \& E$ staining for detecting A/E lesions associated with EHEC O157:H7 infection. This procedure is also useful for differentiating EHEC O157:H7 infections from other infections in calves, as was shown in this study. One control calf had diarrhea and $\mathrm{A} / \mathrm{E}$ lesions 3 days after inoculation with the nonpathogenic $E$. coli strain 123 . However, strain 123 bacteria were not recovered from colonic tissue and $\mathrm{A} / \mathrm{E}$ bacteria were not detected by HRPO staining for O157:H7 (Table 2). We concluded that this control calf was naturally infected with a non-O157:H7 A/E bacterial pathogen.

This study clearly shows that EHEC O157:H7 strains are pathogenic for neonatal calves. This finding is in contrast to previous work $(7,9)$ which demonstrated that EHEC O157:H7 strain 3081 was not pathogenic in cattle $\geq 3$ weeks of age. The neonatal calf model is a relevant model for studying EHEC O157:H7 infections in cattle. We will use this model to identify ways to prevent cattle from becoming infected with EHEC O157:H7 and reduce the risk of EHEC O157:H7 infections in humans.

\section{ACKNOWLEDGMENTS}

We thank D. H. Francis and L. D. Holler for testing EHEC O157:H7 isolates in gnotobiotic piglets, R. Johnson for measuring antibody titers of colostrum, and J. J. Herrick, M. H. Inbody, N. C. Lyon, R. W. Morgan, C. M. Paulin, R. A. Schneider, R. J. Spaete, and J. A. Stasko for technical assistance.

\section{REFERENCES}

1. Blanco, M., J. Blanco, J. E. Blanco, and J. Ramos. 1993. Enterotoxigenic, verotoxigenic, and necrotoxigenic Escherichia coli isolated from cattle in Spain. Am. J. Vet. Res. 54:1446-1451.

2. Casey, T. A. Personal communication.

3. Chanter, N., G. A. Hall, A. P. Bland, A. J. Hayle, and K. R. Parsons. 1986 Dysentery in calves caused by an atypical strain of Escherichia coli (S102-9). Vet. Microbiol. 12:241-253.

4. Chapman, P. A., and C. A. Siddons. 1994. Letter. J. Infect. Dis. 170:251-252.

5. Cheney, C. P., and E. C. Boedeker. 1984. Appearance of host intestinal receptors for pathogenic Escherichia coli with age, p. 157-166. In E. C. Boedeker (ed.), Attachment of organisms to the gut mucosa. CRC Press, Inc., Boca Raton, Fla.

6. Cieslak, P. R., T. J. Barrett, and P. M. Griffin. 1993. Escherichia coli O157:H7 infection from a manured garden. Lancet 342:367.

7. Cray, W. C., Jr., and H. W. Moon. 1995. Experimental infection of calves and adult cattle with Escherichia coli O157:H7. Appl. Environ. Microbiol. 61: 1586-1590.

8. Dean, E. A., S. C. Whipp, and H. W. Moon. 1989. Age-specific colonization of porcine intestinal epithelium by 987 P-piliated enterotoxigenic Escherichia coli. Infect. Immun. 57:82-87.

9. Dean-Nystrom, E. A., B. T. Bosworth, and H. W. Moon. Unpublished data.

10. Faith, N. G., J. A. Sheer, R. Brosch, K. W. Arnold, S. E. Ansay, M.-S. Lee, J. B. Luchansky, and C. W. Kaspar. 1996. Prevalence and clonal nature of Escherichia coli $\mathrm{O} 157: \mathrm{H} 7$ on dairy farms in Wisconsin. Appl. Environ. Microbiol. 62:1519-1525

11. Francis, D. H., R. A. Moxley, and C. Y. Andraos. 1989. Edema disease-like brain lesions in gnotobiotic piglets infected with Escherichia coli serotype O157:H7. Infect. Immun. 57:1339-1342.

12. Francis, D. H., J. E. Collins, and J. R. Duimstra. 1986. Infection of gnotobiotic pigs with an Escherichia coli $\mathrm{O} 157: \mathrm{H} 7$ strain associated with an outbreak of hemorrhagic colitis. Infect. Immun. 51:953-956.

13. Griffin, P. M., L. C. Olmstead, and R. E. Petras. 1990. Escherichia coli O157:H7-associated colitis. A clinical and histological study of 11 cases. Gastroenterology 99:142-148.

14. Griffin, P. M., and R. V. Tauxe. 1991. The epidemiology of infections caused by Escherichia coli $\mathrm{O} 157: \mathrm{H} 7$, other enterohemorrhagic E. coli and the associated hemolytic uremic syndrome. Epidemiol. Rev. 13:60-98.

15. Hall, G. A., D. J. Reynolds, N. Chanter, J. H. Morgan, K. R. Parsons, T. G. Debney, A. P. Bland, and J. C. Bridger. 1985. Dysentery caused by Escherichia coli (S102-9) in calves: natural and experimental disease. Vet. Pathol. 22:156-163.

16. Hancock, D. D., T. E. Besser, M. L. Kinsel, P. I. Tarr, D. H. Rice, and M. G. Paros. 1994. The prevalence of Escherichia coli O157:H7 in dairy and beef cattle in Washington State. Epidemiol. Infect. 113:199-207.

17. Hunt, C. M., J. A. Harvey, E. R. Youngs, S. T. Irwin, and T. M. Reid. 1989. Clinical and pathological variability of infection by enterohemorrhagic (verocytotoxin producing) Escherichia coli. J. Clin. Pathol. 42:847-852.

18. Jerse, A. E., J. Yu, B. D. Tall, and J. B. Kaper. 1990. A genetic locus of enteropathogenic Escherichia coli necessary for the production of attaching and effacing lesions on tissue culture cells. Proc. Natl. Acad. Sci. USA 87:7839-7843.

19. Karmali, M. A. 1989. Infection by verocytotoxin-producing Escherichia coli. Clin. Microbiol. Rev. 2:15-38.

20. Kelly, J. K., A. Oryshak, M. Wenetsek, J. Grabiec, and S. Handy. 1990. The colonic pathology of Escherichia coli O157:H7 infection. Am. J. Surg. Pathol. 14:87-92.

21. Kelly, J. K., C. H. Pai, I. H. Jadusingh, M. L. Macinnis, E. A. Shaffer, and N. B. Hershield. 1987. The histopathology of rectosigmoid biopsies from adults with bloody diarrhea due to verotoxin-producing Escherichia coli. Am. J. Clin. Pathol. 88:78-82.

22. Knutton, S. 1994. Attaching and effacing Escherichia coli, p. 567-591. In 
C. L. Gyles (ed.), Escherichia coli in domestic animals and humans. CAB International, Wallingford, England.

23. Levine, M. M., J. Xu, J. R. Kaper, H. Lior, V. Prado, B. Tall, J. Nataro, H. Karch, and K. Wachsmuth. 1987. A DNA probe to identify enterohemorrhagic Escherichia coli $\mathrm{O} 157: \mathrm{H} 7$ and other serotypes that cause hemorrhagic colitis and hemolytic uremic syndrome. J. Infect. Dis. 156:175-182.

24. Mainil, J. G., C. J. Duchesnes, S. C. Whipp, L. R. M. Marques, A. D. O'Brien, T. A. Casey, and H. W. Moon. 1987. Shiga-like toxin production and attaching effacing activity of Escherichia coli associated with calf diarrhea. Am. J. Vet. Res. 48:743-748.

25. Moon, H. W., and P. L. Runnels. 1984. The K99 adherence system in cattle, p. 31-37. In E. C. Boedeker (ed.), Attachment of organisms to the gut mucosa, vol. 1. CRC Press, Inc., Boca Raton, Fla.

26. Moon, H. W., D. K. Sorensen, and J. H. Sautter. 1968. Experimental enteric colibacillosis in piglets. Can. J. Comp. Med. 32:493-497.

27. Morrison, D. M., D. J. Tyrrell, and L. D. Jewell. 1986. Colonic biopsy in verotoxin-induced hemorrhagic colitis and thrombotic thrombocytopenic purpura (TTP). Am. J. Clin. Pathol. 86:108-112.

28. Moxley, R. A., and D. H. Francis. 1986. Natural and experimental infection with an attaching and effacing strain of Escherichia coli in calves. Infect. Immun. 53:339-346.

29. O'Brien, A. D., and R. K. Holmes. 1987. Shiga and Shiga-like toxins. Microbiol. Rev. 51:206-220.

30. O'Brien, A. D., A. R. Melton, C. K. Schmitt, M. L. McKee, M. L. Batts, and D. E. Griffin. 1993. Profile of Escherichia coli O157:H7 pathogen responsible for hamburger-borne outbreak of hemorrhagic colitis and hemolytic uremic syndrome in Washington. J. Clin. Microbiol. 31:2799-2801.

31. Orskov, F., I. Orskov, and J. A. Villar. 1987. Cattle as reservoir of verotoxinproducing Escherichia coli O157:H7. Lancet ii:276.

32. Richardson, S. E., and M. A. Karmali. 1988. The histopathology of the hemolytic uremic syndrome associated with verocytotoxin-producing Escherichia coli. Hum. Pathol. 19:1102-1108.

33. Riley, L. W., R. S. Memis, S. D. Helgerson, H. B. McGee, H. G. Wells, B. R. Davis, R. J. Hebert, E. S. Olcott, L. M. Johnson, N. T. Hargrett, P. A. Blake, and M. L. Cohen. 1983. Hemorrhagic colitis associated with a rare Escherichia coli serotype. N. Engl. J. Med. 308:681-685.

34. Ryan, C. A., R. V. Tauxe, G. W. Hosek, J. G. Wells, P. A. Stoesz, H. W. McFadden, Jr., P. W. Smith, G. F. Wright, and P. A. Blake. 1986. Escherichia coli $\mathrm{O} 157: \mathrm{H} 7$ diarrhea in a nursing home: clinical epidemiological, and pathological findings. J. Infect. Dis. 154:631-637.

35. Sarmiento, J. I., T. A. Casey, and H. W. Moon. 1986. Postweaning diarrhea in swine: experimental model of enterotoxigenic Escherichia coli infection. Am. J. Vet. Res. 49:1154-1159.

36. Schoonderwoerd, M., R. C. Clarke, A. A. van Dreumel, and S. A. Rawluk 1988. Colitis in calves: natural and experimental infection with a verotoxinproducing strain of Escherichia coli O111:NM. Can. J. Vet. Res. 52:484-487.

37. Sears, C. L., and J. B. Kaper. 1996. Enteric bacterial toxins: mechanisms of action and linkage to intestinal secretion. Microbiol. Rev. 60:167-215.

38. Tarr, P. I. 1994. Review of 1993 Escherichia coli O157:H7 outbreak: western United States. Dairy Food Environ. Sanit. 14:372-373.

39. Thomas, L. A., R. A. Reymann, H. W. Moon, R. A. Schneider, D. R. Cummins, M. G. Beckman, L. Schroeder-Tucker, and K. E. Ferris. 1992. Characterization of serotypes O157:H7 and O157:NM Escherichia coli isolated from dairy heifer feces, p. 83. In Proceedings of the Annual Meeting of the American Association of Veterinary Laboratory Diagnosticians 1992.

40. Tzipori, S., C. W. Chow, and H. R. Powell. 1988. Cerebral infection with Escherichia coli $\mathrm{O} 157: \mathrm{H} 7$ in humans and gnotobiotic piglets. J. Clin. Pathol. 41:1099-1103.

41. Tzipori, S., I. K. Wachsmuth, C. Chapman, R. Birner, J. Brittingham, C Jackson, and J. Hogg. 1986. The pathogenesis of hemorrhagic colitis caused by Escherichia coli O157:H7 in gnotobiotic pigs. J. Infect. Dis. 154:712-716.

42. Wadolski, E. A. J. A. Burris, and A. D. O'Brien. 1990. Mouse model for colonization and disease caused by enterohemorrhagic Escherichia coli O157:H7. Infect. Immun. 58:2438-2445.

43. Wells, J. G., L. D. Shipman, K. D. Greene, E. G. Sowers, J. H. Green, D. N. Cameron, F. P. Downes, M. L. Martin, P. M. Griffin, S. M. Ostroff, M. E. Potter, R. V. Tauxe, and I. K. Wachsmuth. 1991. Isolation of Escherichia coli serotype O157:H7 and other Shiga-like-toxin-producing E. coli from dairy cattle. J. Clin. Microbiol. 29:985-989.

44. Wells, J. G., B. R. Davis, I. K. Wachsmuth, L. W. Riley, R. S. Remis, R. Sokolow, and G. K. Morris. 1983. Laboratory investigation of hemorrhagic colitis outbreaks associated with a rare Escherichia coli serotype. J. Clin. Microbiol. 18:512-520.

45. Whipp, S. C., M. A. Rasmussen, and W. C. Cray, Jr. 1994. Animals as a source of Escherichia coli pathogenic for human beings. J. Am. Vet. Med. Assoc. 204:1168-1175.

46. Wilson, R. A., and D. H. Francis. 1986. Fimbriae and enterotoxins associated with Escherichia coli serogroups isolated from pigs with colibacillosis. Am. J. Vet. Res. 47:213-217.

47. Wray, C., I. McLaren, and G. R. Pearson. 1989. Occurrence of 'attaching and effacing' lesions in the small intestine of calves experimentally infected with bovine isolates of verotoxigenic Escherichia coli. Vet. Rec. 125:365-368.

Editor: P. E. Orndorff 